\title{
DIAGNOSIS AND MANAGEMENT OF INTESTINAL OBSTRUCTION IN DOMESTIC CATS (22 CASES)
}

\author{
MOHAMMED H. ELRASHIDY ${ }^{1}$ and DOAA SALMAN ${ }^{2}$ \\ ${ }^{1}$ Department of Surgery, Anesthesiology and Radiology, Faculty of Veterinary Medicine, Sohag University, \\ Sohag 82524, Egypt. \\ ${ }^{2}$ Department of Animal Medicine, Faculty of Veterinary Medicine, Sohag University, Sohag 82524, Egypt.
}

Received: 29 December 2016; $\quad$ Accepted: 19 January 2017

\begin{abstract}
The present study was carried out on 22 domestic cats to investigate the intestinal obstruction based on the history, clinical signs and radiographic examination and to identify available medical and surgical managements. History, Signalment, and lifestyle of the animals were recorded. Clinical and radiographical examinations were performed to find out the problem. Medical management was performed in 15 cases. Treatment was performed by rectal enema and laxative in (12/15) cases and by manual emptying of impacted anal sacs in (3/15) cases. Surgical intervention was applied in 7 cases that did not respond to medical therapy. Surgery was done to remove intraluminal obstruction in 5 cases, intestinal linear foreign body in one case and abdominal tumor compressing on the intestine in one case. The results clarified a detailed signalment, life style, disease occurrence season, clinical signs of each affected cat. Radiography was helpful for definite diagnosis and determination of location and severity of the obstruction. Medical management was successful to solve the problem in (13/15) cases. However, two cases that suffered from complete intestinal obstruction from several days could not be recovered and died within two days from intervention. Surgical intervention was successful to solve the problem in (4/7) cases. Two cases that suffered from prolonged intestinal obstruction and the case with linear foreign body deteriorated after surgery and died within two days. In conclusion the study provided a clinical presentation for diagnosis and treatment of intestinal obstruction in cats and emphasized that early diagnosis is important to resolve the problem and rescue the cat.
\end{abstract}

Key words: Cat, Intestinal Obstruction, Medical Management, Surgical Intervention.

\section{INTRODUCTION}

Cats are one of the common companion animals worldwide. In Egypt, it was noticed that the gastrointestinal disorders are the most common disorders recorded in cats (Waly and Sayed, 2013). Studies about cats presented with signs of gastrointestinal tract (GIT) disease reported that the obstruction was the primary differential. There are several reasons for the intestinal obstruction include foreign bodies, trichobezoars, focal intestinal neoplasms, and megacolon (MacPhail, 2002). Intestinal obstruction may lead to serious complications caused by fluid and electrolyte imbalances, hypovolemia, and toxemia. Intestinal obstruction causes increase in the intraluminal pathogenic bacterial population as a result of stasis of the intestinal movement. Prolonged luminal distention may reduce the enteric mucosal barrier that increased permeability and access of bacteria and

Corresponding author: Dr. MOHAMMED H. ELRASHIDY E-mail address: elrashidy_egypt@yahoo.com

Present address: Department of Surgery, Anesthesiology and Radiology, Faculty of Veterinary Medicine, Sohag University, Sohag 82524, Egypt. toxins into the systemic circulation or the peritoneal cavity, causing septic peritonitis or endotoxic shock. A significant amount of fluids and electrolytes can be lost in cases of intestinal obstruction, that lead to hypovolemia and electrolyte and acid-base imbalances (Ellison, 1993 and Papazoglou et al., 2003).

Intestinal obstruction can be diagnosed by history and clinical palpation of an abdominal mass. Radiography is used for positive diagnosis and accurate location of the obstruction within the GIT (Chandler et al., 2004). Furthermore, radiography can be used to assess changes in the diameter of feline colon in case of megacolon (Trevail et al., 2011). The conservative and medical management of intestinal obstruction caused by fecal concretion and megacolon may be useful before considering more crucial surgical solutions (Washabau and Holt, 1999; Rosin, 1993). Surgical intervention in some cases is essential to remove the obstruction. Surgical choiceis mainly depends on the degree of the obstruction and whether it is partial or complete (MacPhail, 2002).

The aim of the present study is to investigate intestinal obstruction in domestic cats based on clinical signs and radiographic examination and to 
identify available medical and surgical managements in affected cats.

\section{MATERIALS AND METHODS}

\section{Inclusion criteria of clinical cases}

A retrospective evaluation of 22 domestic cats that presented to the Faculty of Veterinary Medicine, Sohag University with clinical signs that referred to GIT disorders. All cats were owned, some were confined indoor and others were kept indoors but had access to outside. Cats presented with history of vomiting, anorexia, constipation or suspicion of foreign body swallowing. Information taken from cat's owner included signalment (breed, sex, age, and weight), life style, changes encountered defecation and urination acts as complete cessation or reduced amounts and change in food and water intake. Signs of dehydration, abdominal pain and body temperature were also considered. Owners who agreed to involve their cases in the research provided us with information of name; address and telephone number in order to follow up their cats after treatment.

\section{Clinical examination}

Cats were clinically examined by measuring body weights, temperature, breathing and heart rates to rule out any respiratory or circulatory systems involvement. Examination also included general inspection of cat's vitality, body condition, coat, posture, and gait. General behavior, mental and psychological status were encountered. Body regions starting by head, neck, trunk, limbs finally anus and vulva were inspected and palpated to reveal the presence of any abnormalities or pain sensation. Rectal palpation was performed by lubricated figure to examine the presence of obstruction by fecal matter and the consistency of feces.

\section{Radiological examination}

Abdominal radiography was performed to the examined cats. Lateral and ventro-dorsal radiographic views were performed using mobile $\mathrm{X}$-ray machine (Allengers). The hind limbs were secured and pulled caudally to make sure that the stifles are not within the abdominal images. The radiographic setting factors were $60-65 \mathrm{KV}$. and $10-12 \mathrm{mAs}$, with $90 \mathrm{~cm}$ focal spot film distance. The intestine was examined for the presence of changes in the opacity and diameter and the interpretations were recorded.

\section{Medical management}

Rectal enema and therapy

Medical management was performed after sedation of the cases according to the established sedation protocol as using sedative combinations as the following: diazepam $(0.25 \mathrm{mg} / \mathrm{kg})$ and ketamine $\mathrm{Hcl}$ at either 2.5 , or 5.0 , or $7.5 \mathrm{mg} / \mathrm{kg}$, intramuscularly. Higher doses of ketamine were used in excitable cats while lower doses were used in very ill ones (Tennant, 1999). Cats were restrained in ventral or lateral recumbency, tail base grasped and deflected dorsally or laterally. A solution prepared by mixing warm water and laxative as lactulose was used through a disposable polyethylene rectal enema tube to break and soften the hard feces.

In mild cases of constipation, (4/22), cats were responsive to laxatives, fecal softener treatment. We prescribed lactulose to be administered orally by owner three times/ day that was helpful and could relief the constipation within hours to one day. However, when fecal concretion was found in the anus during examination $(8 / 22)$ that was associated with severe pain and urgency, rectal enemas were the first aid. Trials to break concretions and softening the feces by a mixture of warm water and lactulose were performed using polyethylene tubes. Following this intervention, dietary management with soft easily digestible food as chicken soap and yogurt was suggested to cat owners.

In cats suffered from impaction of anal sacs (3/22), when sacs were filled and failed to be emptied normally, manual emptying was made after raising the cat's tail. Sacs could be felt as small pea-size lumps in the perianal areas at the four o'clock and eight o'clock positions (Banks, 1993). After locating the openings the skin surrounding the sacs was grasped with the thumb and forefinger and squeezed together. As the sacs empty, secretions were wiped away with cotton soaked by warm water. In cases of bloody or purulent discharges a local antibiotic cream was used immediately that followed by a systemic one.

The adopted lines of treatment in clinical cases were as following: in dehydrated cases fluid therapy was given by subcutaneous or intravenous injection of physiological saline $(0.85 \% \mathrm{NaCl}$ and lactated ringer at a rate of $60 \mathrm{ml} / \mathrm{kg} / 24$ hour once or twice according to severity of dehydration). Fluid therapy was immediately started at all dehydrated cases. Antimicrobial agents were administered also to treat systemic infections and to avoid secondary bacterial invasion after accomplishment of rectal enema or evacuation of anal sacs. Oral dose of cefalaxin was used (10-30 mg/kg, per os, twice daily for 7 days). Muscle anti-spasmodics, as Diazepam was used for relaxing smooth muscles and to decrease the acute clinical signs at the following dose: half tablet of diazepam $(5 \mathrm{mg}$ ) once daily for 2 successive days. Anti-inflammatory agents, dexamethasone was used in clinical cases for counteracting inflammation (Total dose: $0.01-0.16 \mathrm{mg} / \mathrm{kg}$, once daily per os, for 3-5 days) according to Tennant (1999).

\section{Surgical intervention}

Cats with chronic constipation did not respond to appropriate medical therapies (7/22) required surgical intervention. Surgery was performed under general anesthesia using a combination of Ketamine $\mathrm{Hcl} 5$ 
$\mathrm{mg} / \mathrm{Kg}$ and xylazine $\mathrm{Hcl} 1 \mathrm{mg} / \mathrm{kg}$ intramuscular (Hall et al., 2001). Cats were prepared aseptically in dorsal recumbency and a ventral midline celiotomy was performed from umbilicus to pubis to allow assessment of the gastrointestinal tract. Systemic evaluation of the intestine was performed to localize the site of obstruction. The affected intestinal segment was exteriorized and isolated from the other viscera by moistened drapes.

Five cats were suffered from colon segment (6-10 $\mathrm{cm}$ ) obstruction by solid materials (Fig.1). Trials for gentle milking the obstructed materials distally to be retrieved through the anus were failed. Enterotomy was performed over the obstructed area in the antimesenteric border to remove the obstructed materials (Fig.2). The enterotomy incisions were closed in a single layer with simple interrupted pattern by using 2-0 polygalactin 910 (vicryl®).

One cat was admitted with signs of intestinal obstruction, a $10 \mathrm{~cm}$ long thread appeared protruded from the anus which showed sever signs of colic and pain when grasping the thread slowly. The owner reported that the animal was playing with a thread ball two days before appearance of pain signs.

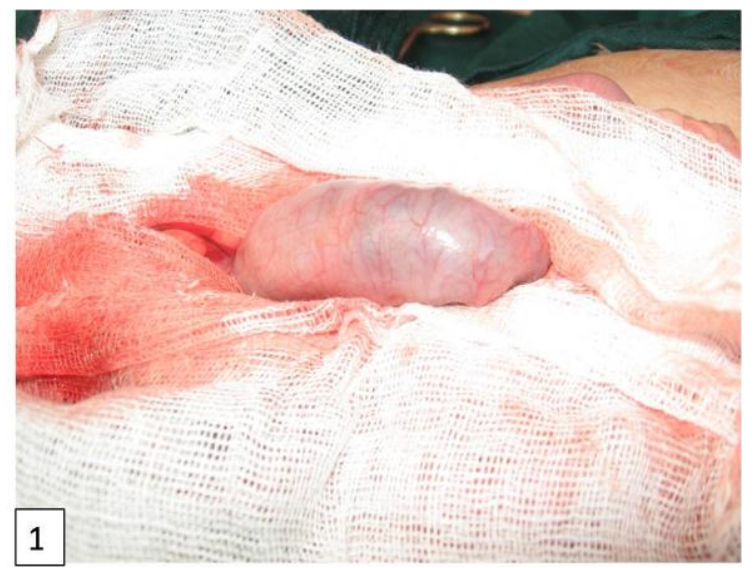

Figure 1: Colon segment obstruction by solid materials

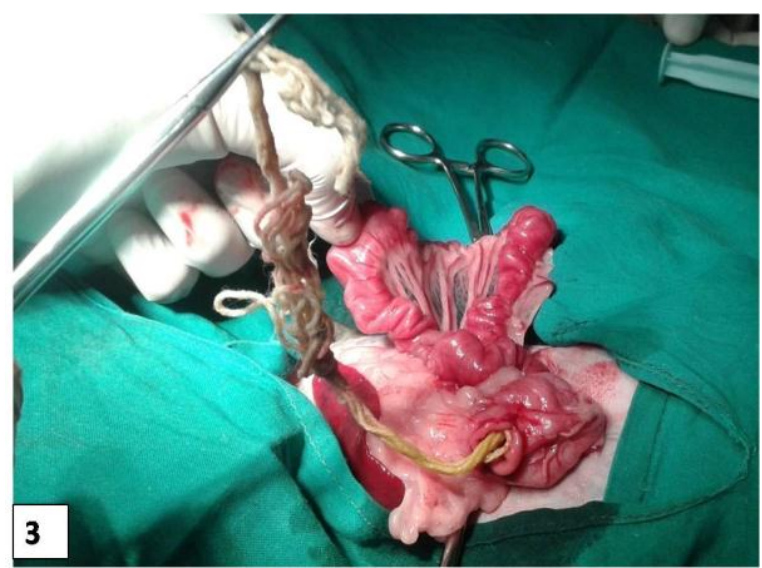

Figure 3: Removal of a linear foreign body from the intestine
Celiotomy was performed to determine site and degree of obstruction. Examination showed intestinal plication and the thread was felt along the lumen of a large portion of the small intestine and the colon. Three enterotomies were performed to complete removal of the foreign body (Fig3).

A male cat was admitted with signs of constipation and dysuria. Abdominal examination followed celiotomy showed presence of a pedunculated tumour originated from the wall of the abdominal cavity and extended between the urinary bladder and the intestine (Fig.4). Surgical excision of the tumour mass was performed to relieve pressure on the intestine and urinary bladder. Gentle massage of the colon was performed without enterotomy to evacuate the content. Adopted medical management of constipation and urinary bladder catheterization was applied post-operatively.

Finally the abdominal cavity was lavaged with warm sterile saline and the celiotomy incision was closed routinely. Postoperatively fluid therapy and oral doses of cefalax in were used.

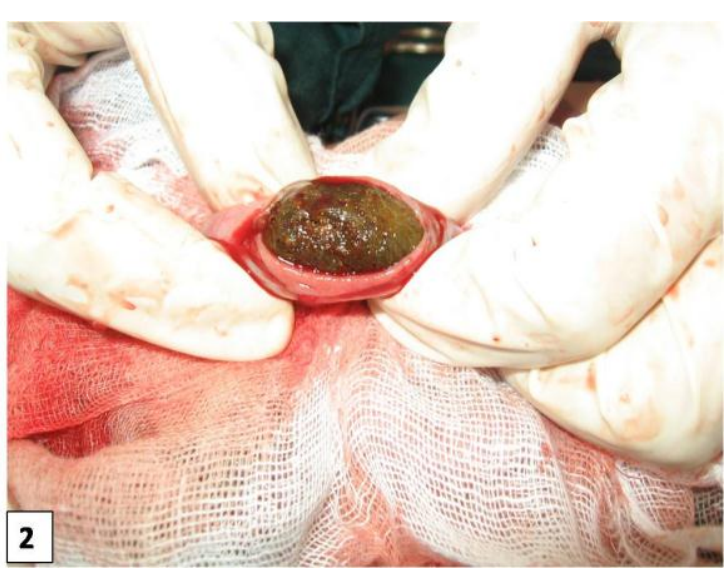

Figure 2: Enterotomy over the obstructed area in the antimesenteric border

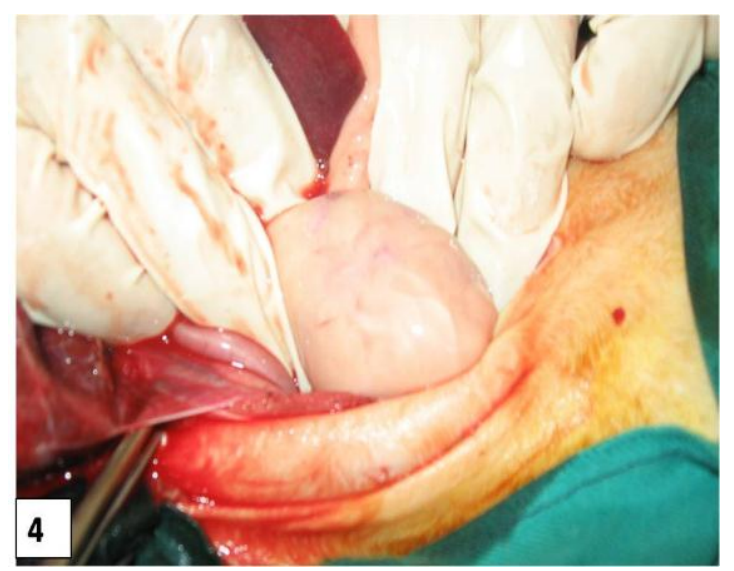

Figure 4: Pedunculated tumour originated from the abdominal cavity 


\section{RESULTS}

Intestinal obstruction was reported in 22 cats. Most of them were long hair breeds (14/22) either Persian (9) or Persian cross-bred (4) and one cat belonged to Turkish Angora breed. While Egyptian domestic short hair cats were $(8 / 22)$. The majority of cases were males (17/22) and the rest (5/22) were females. Age was variable (3 months to 7 years old). Most cases were over one year old $(15 / 22)$ and 3 cases were of unknown exact age. Body weight of the cases was measured at time of presentation and ranged from 1.5 to 6 kilograms. Life style of cats was recorded as complete confinement indoor (10/22), live indoor but have access to outside $(6 / 22)$ and cats that lived mostly outside (6/22) as illustrated in (table. 1).

Diet of these cats was consisting of different food stuff as fish, cheese, meat, boiled chicken parts especially legs and dry food. Cats that had access to go outside were also consumed different kinds of preys, while commercially available dry food was commonly supplied to those confined indoor. Considering the season and disease occurrence, it was noticed that most of cases $(14 / 22)$ were presented at winter season (December to February) only 4 clinical cases had come at summer season between July and September. Four cases were presented in spring between April and June (table .1).

General appearance of cats was scored as depressed or active. Depressed cats were lethargic, easy to be handled, have altered awareness to the surroundings and not responding to stimuli and sounds. Signs of depression were observed in 20 cases. The degree of depression was also variable according to the severity and chronicity of the cases. Only two cats were active, bright and aware of the surroundings, alert and responsive, and of normal appetite. Four cases showed reduced appetite and the majority suffered from anorexia (16/19), however, two cases were had normal appetite. We also asked owners if their cats were drinking water as usual or not. Drinking was found to be normal in (7/22) cases, reduced in (8/22) cases and completely stopped in the deteriorated severe cases (7/22) as (table.2).

Body temperature of cases was measured rectally and was within the normal range $\left(38.5\right.$ to $39.5{ }^{\circ} \mathrm{C}$ ) in most of them (19/22). Only cases numbered 3 and 12 showed a considerably slight hyperthermia (41 and $40.3{ }^{\circ} \mathrm{C}$ respectively) and case number 18 was hypothermic $\left(37.5{ }^{\circ} \mathrm{C}\right)$. Thirteen cases showed vomiting, two of them had hair in their vomitus materials and the rest had no history of vomiting. Signs of dehydration were observed in 18 cases, dehydration was inspected by signs of poor skin elasticity (tested by skin folding) and sunken eyes that were associated with general emaciation and poor condition. Signs of abdominal pain were reflected by crouched position and painful palpation that found in most of cases (17/22). Urination was normal in 9 cats, reduced in two, and 8 had anuria and the remaining 3 cats could not be observed by owners (table. 2).

Table 1: Signalment and living style of cat patients

\begin{tabular}{|c|c|c|c|c|c|c|}
\hline Case Number & Breed & Sex & Age $(\mathrm{y}, \mathrm{mo})$ & $\begin{array}{l}\text { Body weight }(\mathrm{kg}) \\
\text { at presentation }\end{array}$ & Living style & Season \\
\hline 1 & Persian & Male & 1,6 & 4.5 & Confined indoor & Winter \\
\hline 2 & $\begin{array}{l}\text { Egyptian domestic } \\
\text { short hair }\end{array}$ & Female & unknown & 2 & Mostly indoor & Spring \\
\hline 3 & Persian cross & Male & 0,7 & 1.5 & Mostly indoor & Winter \\
\hline 4 & Angora & Male & 0,5 & 2.5 & Confined indoor & Summer \\
\hline 5 & $\begin{array}{l}\text { Egyptian domestic } \\
\text { short hair }\end{array}$ & Male & 1,5 & 2.3 & Mostly outdoor & Winter \\
\hline 6 & Persian & Male & unknown & 2 & Mostly outdoor & Winter \\
\hline 7 & $\begin{array}{l}\text { Egyptian domestic } \\
\text { short hair }\end{array}$ & Female & 1,5 & 1.8 & Mostly outdoor & Winter \\
\hline 8 & Persian & Male & 0,7 & 3 & Confined indoor & Spring \\
\hline 9 & $\begin{array}{l}\text { Egyptian domestic } \\
\text { short hair }\end{array}$ & Male & unknown & 3.5 & Mostly indoor & Winter \\
\hline 10 & Persian & Female & 1,3 & 1.4 & Mostly indoor & Winter \\
\hline 11 & Persian & Male & 1,2 & 1.5 & Mostly indoor & Winter \\
\hline 12 & $\begin{array}{l}\text { Egyptian domestic } \\
\text { short hair }\end{array}$ & Male & 1,3 & 3.5 & Mostly outdoor & Summer \\
\hline 13 & Persian cross & Male & 0,3 & 2 & Confined indoor & Spring \\
\hline 14 & $\begin{array}{l}\text { Egyptian domestic } \\
\text { short hair }\end{array}$ & Male & 3,0 & 4 & Mostly outdoor & Winter \\
\hline 15 & $\begin{array}{l}\text { Egyptian domestic } \\
\text { short hair }\end{array}$ & Male & 2,0 & 2 & Mostly outdoor & Winter \\
\hline 16 & Persian & Female & 1,0 & 1.3 & Confined indoor & Winter \\
\hline 17 & Persian cross & Male & 6,0 & 6 & Confined indoor & Summer \\
\hline 18 & Persian & Male & 3,0 & 3 & Confined indoor & Winter \\
\hline 19 & Persian cross & Male & 5,0 & 4 & Confined indoor & Spring \\
\hline 20 & Persian & Male & 3 & 3 & Confined indoor & Winter \\
\hline 21 & Persian & Female & 1.5 & 2.5 & Confined indoor & Summer \\
\hline 22 & $\begin{array}{l}\text { Egyptian domestic } \\
\text { short hair }\end{array}$ & Male & 7 & 3 & Mostly indoor & Winter \\
\hline
\end{tabular}


Table 2: History, clinical signs, management and outcome of cat patients

\begin{tabular}{|c|c|c|c|c|c|c|c|c|c|c|}
\hline $\begin{array}{l}\text { Case } \\
\text { Number }\end{array}$ & $\begin{array}{c}\text { General } \\
\text { Appearance }\end{array}$ & Appetite & $\begin{array}{l}\text { Water } \\
\text { Intake }\end{array}$ & $\begin{array}{c}\text { Temperature } \\
\left({ }^{\circ} \mathrm{C}\right)\end{array}$ & Vomiting & Dehydration & $\begin{array}{c}\text { Signs of } \\
\text { abdominal } \\
\text { pain }\end{array}$ & Urination & Management & Recovery \\
\hline 1 & Active & Normal & Normal & 39 & Y (Hair) & Y & $\mathrm{N}$ & Normal & surgical & $\mathrm{Y}$ \\
\hline 2 & Depressed & Reduced & Normal & 39.5 & $\mathrm{Y}$ & Y & $\mathrm{N}$ & Normal & Medical & $\mathrm{Y}$ \\
\hline 3 & Depressed & Anorexia & Stopped & 41 & Y & $\mathrm{N}$ & $\mathrm{Y}$ & Normal & Medical & $\mathrm{Y}$ \\
\hline 4 & Depressed & Anorexia & Normal & 39 & $\mathrm{~N}$ & $\mathrm{Y}$ & $\mathrm{N}$ & Normal & Medical & $\mathrm{Y}$ \\
\hline 5 & Depressed & Anorexia & Stopped & 38.7 & $\mathrm{Y}$ & $\mathrm{Y}$ & $\mathrm{Y}$ & $\begin{array}{c}\text { Not } \\
\text { observed }\end{array}$ & Medical & $\mathrm{Y}$ \\
\hline 6 & Depressed & Reduced & Normal & 39.5 & Y (Hair) & $\mathrm{N}$ & $\mathrm{N}$ & Normal & Surgical & $\mathrm{Y}$ \\
\hline 7 & Depressed & Anorexia & Normal & 38.9 & Y & $\mathrm{Y}$ & $\mathrm{Y}$ & $\begin{array}{c}\text { Not } \\
\text { observed }\end{array}$ & Medical & $\mathrm{Y}$ \\
\hline 8 & Depressed & Reduced & Normal & 39.3 & $\mathrm{~N}$ & $\mathrm{Y}$ & $\mathrm{Y}$ & Normal & Medical & $\mathrm{Y}$ \\
\hline 9 & Depressed & Anorexia & Stopped & 39 & $\mathrm{Y}$ & $\mathrm{Y}$ & $\mathrm{Y}$ & Stopped & Medical & $\mathrm{N}$ \\
\hline 10 & Depressed & Anorexia & Stopped & 39 & $\mathrm{~N}$ & Y & Y & Stopped & Surgical & $\mathrm{N}$ \\
\hline 11 & Depressed & Anorexia & Reduced & 39.4 & $\mathrm{~N}$ & Y & $\mathrm{Y}$ & Stopped & Medical & $\mathrm{Y}$ \\
\hline 12 & Depressed & Anorexia & Reduced & 40.3 & $\mathrm{~N}$ & $\mathrm{Y}$ & $\mathrm{Y}$ & Normal & Medical & $\mathrm{Y}$ \\
\hline 13 & Active & Normal & Normal & 39 & $\mathrm{~N}$ & $\mathrm{~N}$ & $\mathrm{~N}$ & Normal & Medical & $\mathrm{Y}$ \\
\hline 14 & Depressed & Anorexia & Reduced & 38.5 & $\mathrm{~N}$ & $\mathrm{Y}$ & $\mathrm{Y}$ & $\begin{array}{c}\text { Not } \\
\text { observed }\end{array}$ & Medical & $\mathrm{Y}$ \\
\hline 15 & Depressed & Anorexia & Stopped & 38.5 & $\mathrm{Y}$ & $\mathrm{Y}$ & $\mathrm{Y}$ & Stopped & Medical & $\mathrm{Y}$ \\
\hline 16 & Depressed & Anorexia & Stopped & 39 & $\mathrm{Y}$ & $\mathrm{Y}$ & $\mathrm{Y}$ & Stopped & Medical & $\mathrm{Y}$ \\
\hline 17 & Depressed & Anorexia & Reduced & 39.5 & $\mathrm{Y}$ & $\mathrm{Y}$ & $\mathrm{Y}$ & Reduced & Medical & $\mathrm{Y}$ \\
\hline 18 & Depressed & Anorexia & Stopped & 37.5 & Y & Y & Y & Stopped & Medical & $\mathrm{N}$ \\
\hline 19 & Depressed & Reduced & Reduced & 39.5 & $\mathrm{~N}$ & Y & Y & Stopped & Surgical & $\mathrm{Y}$ \\
\hline 20 & Depressed & Anorexia & Reduced & 39.4 & $\mathrm{Y}$ & $\mathrm{Y}$ & $\mathrm{Y}$ & Normal & Surgical & $\mathrm{N}$ \\
\hline 21 & Depressed & Anorexia & Reduced & 39 & $\mathrm{~N}$ & $\mathrm{~N}$ & $\mathrm{Y}$ & Reduced & Surgical & $\mathrm{N}$ \\
\hline 22 & Depressed & Anorexia & Reduced & 39.5 & $\mathrm{Y}$ & Y & $\mathrm{Y}$ & Stopped & Surgical & $\mathrm{Y}$ \\
\hline
\end{tabular}

$\mathrm{Y}($ yes $), \mathrm{N}(\mathrm{NO})$

\section{Radiographic finding}

Survey abdominal radiography showed enlargement of the obstructed segment with heterogeneous radiopaque material, and gas distension proximal to the obstruction (Fig. 5\&6). Abdominal radiography of the cat with linear foreign body obstruction showed intestinal plication with gas dilation (Fig. 7).

\section{Medical management}

All cases involved in the study were primarily managed medically either by rectal enemas or evacuation of impacted anal sacs. Cases that did not respond or could not be solved medically were referred to the surgical intervention $(7 / 22)$.

Follow up cats treated medically (15/22) showed improvement in the defecation status after removal of the cause in 13 cats. Dehydrated cases recovered within 1-3 days of management. Unfortunately, 2 cases that suffered from complete intestinal obstruction by fecal concretion for several days that was associated with severe dehydration states and depression accompanied by anuria and anorxia had no chances to be solved medically even after trials with rectal enema. Adding, the very poor health conditions of those cats did not allow any surgical intervention. These cats died within two days from intervention (table. 2).

\section{Surgical intervention}

Surgical intervention in cats did not respond to medical management (7/22) revealed that, intestinal obstruction occurred from intraluminal solid fecal material (5/7), intraluminal linear foreign body (1/7), and extraluminal compression with a tumour mass (1/7). Intraluminal solid fecal material was fecal 
concretion in three cats and spherical ball of hair with fecal matter (trichobezoars) in two persian cats.

Cat with linear foreign body required three enterotomies for complete removal. The intestine was bunched, congested, and emptied from ingesta. Surgical management of the cat with intestinal obstruction from extraluminal compression of tumour

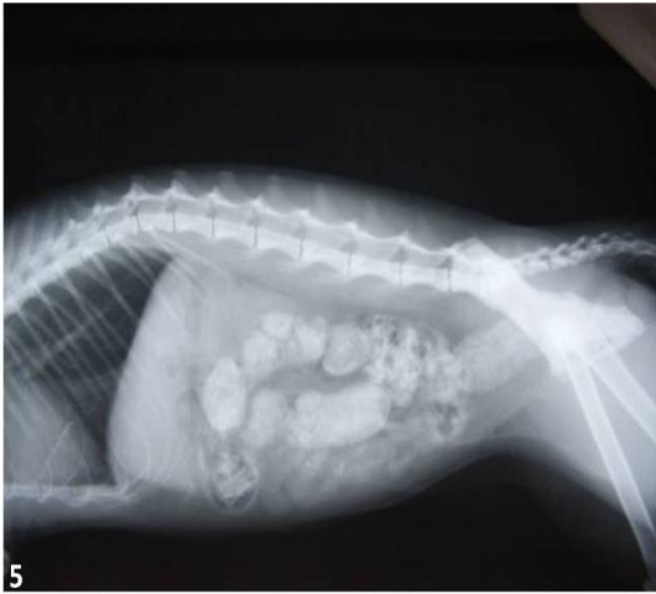

Figure 5: Lateral radiographic view of the abdomen showing enlargement of the obstructed segment with heterogeneous radiopaque material mass was restricted to surgical removal of the cause of obstruction without enterotomy.

Surgical outcomes: four of the operated cats recovered completely. The cat operated for removal of linear foreign body and two cats operated for removal of fecal concretion obstruction from two days showed signs of depression and dehydration postoperatively. The three cats died two days after operation (table. 2).

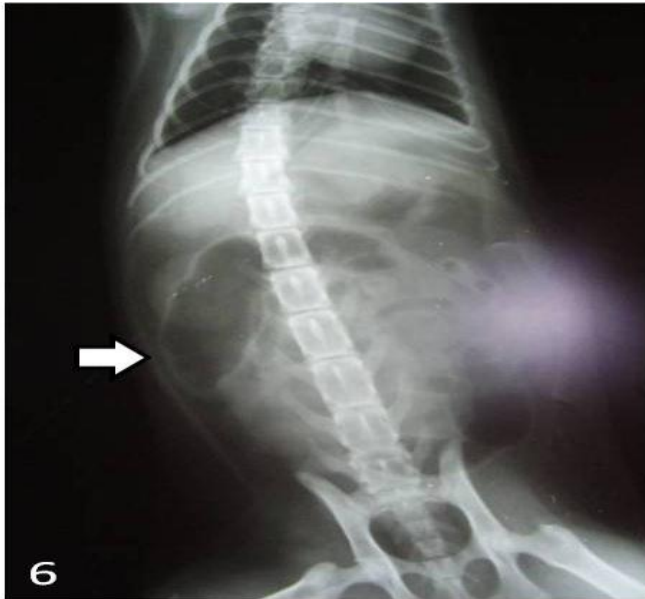

Figure 6: Ventro-dorsal radiographic view of the abdomen showing gas distension proximal to the obstruction (white arrow)

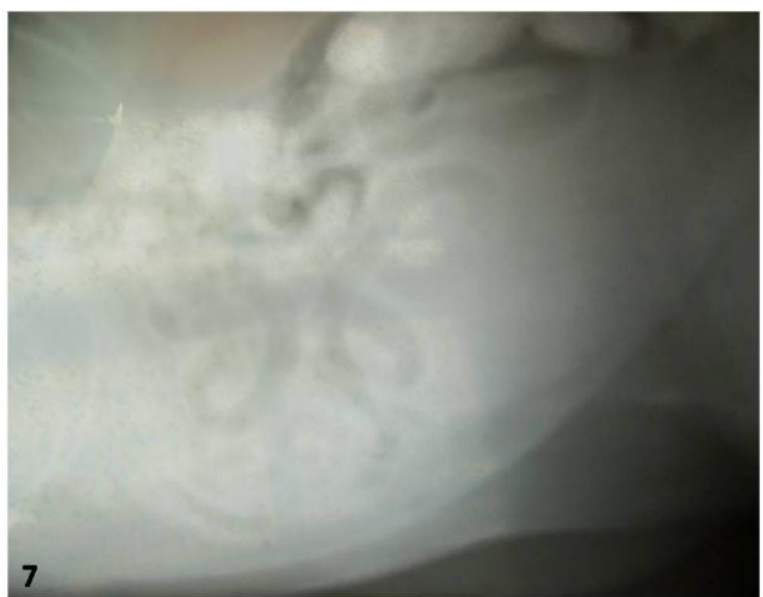

Figure 7: Lateral radiographic view of the abdomen showing intestinal plication with gas dilation

\section{DISCUSSION}

Intestinal obstruction is a common affection of the domestic cat. There are many expected causes of the intestinal obstruction and the management of the condition depends on the clinician's ability to identify the proper etiology in each case (White, 2002). Intestinal obstruction should be included in the differential diagnosis of a cat with acute vomiting, anorexia and abdominal pain. The clinical picture depends on the degree of obstruction, location of obstruction and changes in intestinal blood flow
(Washabau and Holt, 1999). Abdominal radiography is useful in the diagnostic assessment of the site of obstruction, the severity of the intestinal impaction and the obstructing cause (chandler et al., 2004). The present study is focusing on diagnosis of intestinal obstruction based on the clinical picture and radiographic finding and the possible management of the affected cats.

Clinical signs reported in cases of intestinal obstruction were mainly vomiting, constipation, tenesmus, anorexia and weight loss. During history 
taking from owners about their cat's problem, several factors were recorded and put into consideration. These factors included diet, living environment, activity, season, breed, sex and body weight. These factors may be predisposed to the occurrence of GIT disorders in cats (table. 1). Regarding the environment at which the cat lived, most of clinical cases were lived indoor either completely or mostly. Cats usually spend all or most of time with humans and also use a litter tray for urination and defecation. This restricted environment rendered cats inactive and did little exercise and subsequently increased the risk of constipation according to our observations. Most of cases were associated with vomiting and signs of dehydration. Vomiting was observed in the severe degree of distension and complete obstruction of GIT. This could be attributed to the stretching of GIT wall, which in turn sends stimulating signals to vomiting center in brain (Lees, 2004). In addition, retention of urine and distended urinary bladder that also found in some cases either as a result of feline lower urinary tract disease or secondary due to distended GIT for long time is another factor led to vomiting. Perhaps also urine retention passively affected kidneys function and led to uremia and vomiting (Lunn, 2006). In some cases of long standing vomiting we observed severe weakness of muscles that associated with hypokalemic posture (Ha et al., 2013). Further, most of cases encountered in this study were presented at winter could be explained by the reduced water intake during cold weather (Cunningham \& Klein, 2007). The combination between reduced water intake during winter and inactivity due to indoor confinement adding to that the nature of diet that consists mainly of commercial dry food, altogether are considered powerful predisposing factors for the GIT hypomotility in owned cats that reflected clinically by intestinal obstruction and further constipation in these cases.

Medical management includes maintaining hydration, enemas, laxatives, pain control medications, dietary changes, and removal of impacted feces is the first approach to cats with mild to moderate constipation. However, as they progress to chronic constipation and dilated megacolon, these cats eventually require surgical approach (Washabau and Holt, 1999 and White, 2005).

The study stated that chronic cases of constipation did not respond to medical therapies, and should be managed surgically to relief the intestinal obstruction. Prolonged periods of constipation lead to the removal of excessive amount of moisture from the fecal matter with consequent concretion. Delayed management of the condition lead to development of a persistent enlargement of a flaccid hypomotile colon and rectum (Chandler et al., 2004 and White, 2005). Trichobezoars were removed from two Persian cats.
Because the fastidious grooming habits and barbed tongues of the cat a significant amount of hair accumulated in the GIT, then they could be vomited or passed undigested into the intestine. The ingestion of hair should be considered as a potential cause of intestinal obstruction, particularly in long hair breeds (Barrs el al., 1999).

Intestinal obstruction with linear foreign bodies causes extensive damage to the intestinal tract. Movement of the linear foreign body distally with peristaltic waves lead to gathering the intestine around the foreign body and the small intestine forms circular loops because of the mesenteric restriction (Papazoglou, 2003). In the present study the operated cat required three enterotomies to complete removal of the linear foreign body. the intestinal obstruction was recorded in the present study in one case due to extra-luminal pressure from a pedunculated tumour originated from the abdominal cavity. Relieving the pressure on the intestine improved the case without need to enterotomy.

Four cats suffered from prolonged complete intestinal obstruction by fecal concretiondied followed medical management ( 2 cases) or surgical intervention (2 cases). The prolonged distention of the large intestine may lead to development of irreversible dilatation and loss of mobility (White, 2005). Therefore, subtotal colectomy with preservation of ileocolic junction should be considered for surgical management chronic cases of low bowel obstruction (White, 2002).

Finally, it is important from the medical point of view to teach cat's owners the preventive measures to minimize disease recurrence by advice to increase water intake, provide semi-moist food, regular cat exercise and regular observation of the cat defecation and urination behavior, as early diagnosis is important to resolve the problem and rescue the cat.

In conclusion, the present research provides a preliminary study about risk factors, clinical presentation and medical and surgical management of intestinal obstruction in domestic cats. In addition we referred to possible complications and outcomes as this condition can be a recurring problem in many cats if the predisposing factors are still present. This study can be helpful to the veterinarians in this field to understand the early management of GIT obstruction in cats especially those presented as emergencies.

\section{ACKNOWLEDGMENT}

The authors are grateful to Professors Dr. Nashwa E. Waly and Dr. Magda M. Ali (Faculty of Veterinary Medicine, Assiut University, Assiut, Egypt) for their technical advice and support. 


\section{REFERENCES}

Banks, W.J. (1993): Applied Veterinary Histology, $3^{\text {rd }}$ Ed., Mosby Year Book, St. Louis, MO.pp: 298-325.

Barrs, V.R.; Beatty, J.A.; Tisdall, P.L.C.; Hunt, G.B.; Gunew, M.; Nicoll, R.G. and Mallik, R. (1999): Intestinal obstruction by trichobezoars in five cats. Journal of feline medicine and surgery. 1(4): 199-207.

Chandler, E.A.; Gaskell, C.J. and Gaskell, R.M. (2004): Feline medicine and therapeutics. $3^{\text {rd }}$ Ed., Blackwell publishing. pp: 414-434.

Cunningham, J.G. and Klein, B.G. (2007): Veterinary physiology $4^{\text {th }}$ Ed. Chapter 44. Saunders Elsevier, INC. pp: 556-563.

Ellison, G.W. (1993): Intestinal obstruction. Bojrab MJ: Disease Mechanisms in Small Animal Surgery $2^{\text {nd }}$ Ed., Philadelphia, Lea and Febiger. Pp: 252-257.

Ha, Y.S.; Hopper, K. and Epstein, S.E. (2013): Incidence, nature, and etiology of metabolic alkalosis in dogs and cats. Journal of Veterinary Internal Medicine. 27(4): 847-853.

Hall, L.W.; Clarke, K.W. and Trim, C.M. (2001): Anaesthesia of the cat. Veterinary anaesthesia, $10^{\text {th }}$ Ed. W. B., Saunders, England.PP: 450455.

Lees, G.E. (2004): Early diagnosis of renal disease and renal failure. Veterinary Clinics of North America, Small Animal Practice.34: 867- 885.

Lunn, K.F. (2006): Approach to Azotaemia. Scientific Proceedings, British Small Animal Veterinary Association. $49^{\text {th }}$ Annual Congress, ICC/NIA Birmingham, UK. April 20-23. pp.
365-367.

MacPhail, C. (2002): Gastrointestinal obstruction. Clinical Techniques in Small Animal Practice. 17(4):178-183.

Papazoglou, L.G.; Patsikas, M.N. and Rallis, T. (2003): Intestinal foreign bodies in dogs and cats. Compendium. 25 (11): 830-844.

Rosin, E. (1993): Megacolon in cats. The role of colectomy. Veterinary Clinics of North America: Small Animal Practice. 23(3): 587594.

Tennant, B. (1999): Small Animal Formularly. (3 ${ }^{\text {rd }}$ Ed.). British Small Animal Veterinary Association. UK. pp. 282-283.

Trevail, T.; Gunn-Moore, D.; Carrera, I.; Courcier, E. and Sullivan, M. (2011): Radiographic diameter of the colon in normal and constipated cats and in cats with megacolon. Vet Radiol Ultrasound. 52(5): 516-520.

Waly, N.E. and Sayed, R.K. (2013): Demography of small animal clinical cases in Egypt. Journal of veterinary internal medicine (abstract). 27: 747- 747.

Washabau, R.J. and Holt, D. (1999): Pathogenesis, diagnosis, and therapy of feline idiopathic megacolon. Veterinary Clinics of North America: Small Animal Practice. 29(2): 589603.

White, R.A.S. (2005): Managing the constipated cat. The North American Veterinary Conference proceedings January 8-12. pp: 375-376.

White, R.N. (2002): Surgical management of constipation. Journal of Feline Medicine and Surgery. 4(3):129-138.
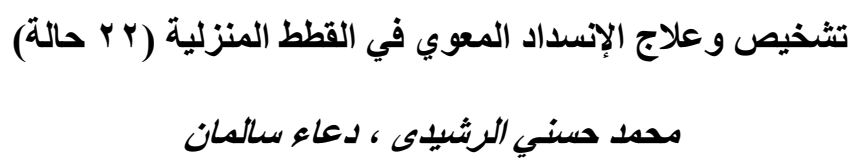

Email: elrashidy_egypt@yahoo.com Assiut University web-site: www.aun.edu.eg

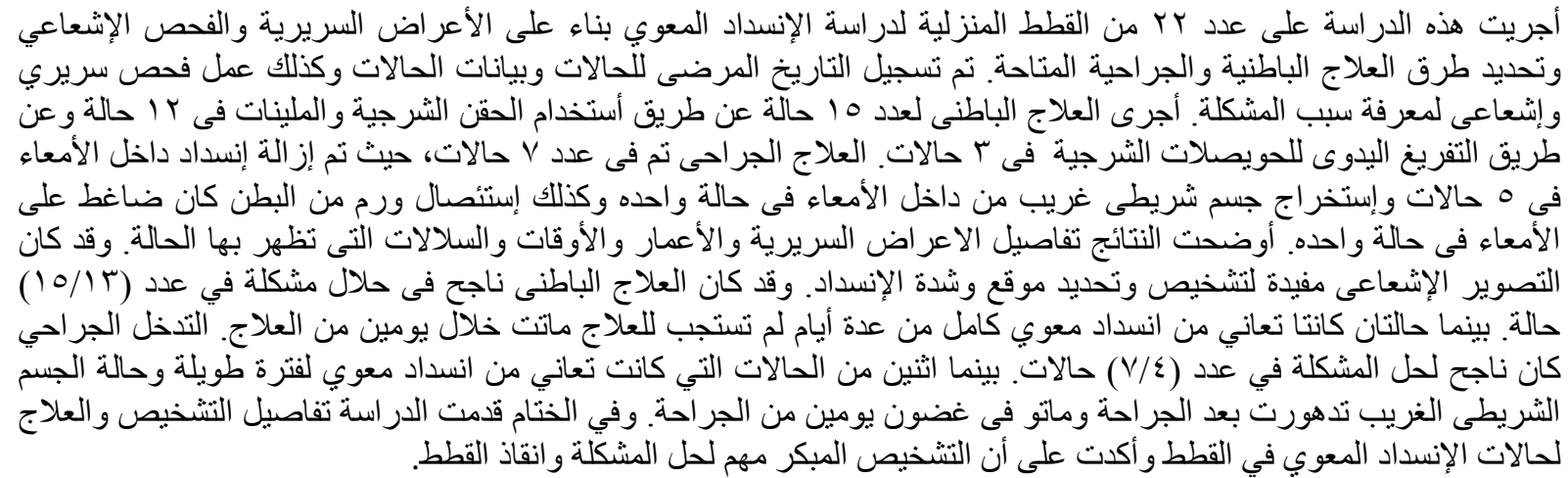

